REVIEW

\title{
Testing for thrombophilia: an evidence-based approach
}

\author{
L Merriman, M Greaves
}

Postgrad Med J 2006;82:699-704. doi: 10.1136/pgmi.2006.048090

Thrombophilia is a disorder of haemostasis in which there is a tendency for the occurrence of thrombosis. This tendency can be inherited or acquired. This review outlines common acquired and inherited thrombophilic conditions and discusses indications for testing. It is concluded that testing for acquired thrombophilic conditions should be considered in all cases of venous thrombosis, whereas testing for inherited thrombophilic conditions is unlikely to be helpful. If testing for inherited thrombophilia is to be carried out, the benefits, pitfalls and unwanted consequences of such testing should be taken into account.

See end of article for authors' affiliations .........

Correspondence to: Dr L Merriman, Ward 16, Aberdeen Royal Infirmary, Cornhill Road, Aberdeen AB25 2ZN, UK; kim.luke@paradise.net.nz

Received 27 March 2006 Accepted 2 June 2006
T hrombophilia is a disorder of haemostasis in which there is a tendency for the occurrence of thrombosis (MeSH). This tendency can be inherited or acquired. In general, heritable thrombophilia is associated with a predisposition to venous, not arterial, thromboembolism. The purpose of this review is to outline a practical approach to testing for thrombophilia. In relation to the utility of testing for thrombophilia, we will concentrate on inherited thrombophilic defects, as there is often confusion about the use of testing for these. We will attempt to use the published literature to justify our recommendations, but where there is controversy we will outline our own approach and the justification for this. UK national guidelines on testing for heritable thrombophilia have also been published. ${ }^{1}$

\section{ACQUIRED THROMBOPHILIA}

In many cases of venous thromboembolism (VTE), there is an obvious precipitating factor, such as the postoperative state. In a minority, VTE is apparently unprovoked or spontaneous. Acquired thrombophilic conditions should be considered in all cases of apparently spontaneous VTE (table 1). Identifying such a condition may have important management implications for the patient, as anticoagulant treatment may minimise the risk of thrombosis recurrence. If the precipitating factor is not reversible then longterm anticoagulation may be indicated. Some conditions, such as obesity, inflammatory bowel disease and overt malignancy, may be easily identified. Four other acquired conditions associated with thrombosis require specific consideration.

\section{Occult malignancy}

Cancer is diagnosed in around 10\% of patients within 6 months of presentation with apparently spontaneous deep vein thrombosis (DVT). ${ }^{23}$
Many of these cancers can be diagnosed at the time venous thrombosis is identified through thorough clinical assessment. ${ }^{2}$ Although more extensive screening, including thoracoabdominal computed tomography scanning at the time of VTE diagnosis, has been shown to identify clinically occult malignancy, ${ }^{3}$ there is no evidence that earlier diagnosis leads to improved clinical outcomes. The cost effectiveness of random screening for occult malignancy in patients presenting with VTE is open to doubt. It is generally recommended that a careful history and physical examination be carried out with further investigations ordered only as clinically indicated. Unexplained early recurrence, or progression despite adequate anticoagulation, may reasonably trigger further investigation.

\section{Myeloproliferative disease}

The two most common myeloproliferative disorders, essential thrombocythaemia and polycythaemia vera, are both associated with thrombosis in the venous, arterial and microvascular compartments. Venous thrombosis may be found in atypical sites (especially intraabdominal). Careful examination of the blood count and clinical examination for splenomegaly should be carried out in patients with apparently unexplained thrombosis.

\section{Paroxysmal nocturnal haemoglobinuria}

This acquired clonal stem cell disorder results in a triad of thrombosis, haemolysis and marrow aplasia, but not all three features are necessarily present. Mutation in the phosphatidylinositol glycan class A gene leads to loss of glycosylphosphatidylinositol anchors on blood cells, and hence loss of a variety of surface molecules that rely on the glycosylphosphatidylinositol anchor. In the case of red blood cells, loss of expression of CD55 and CD59 leads to increased sensitivity to complement, and hence to intravascular haemolysis. The patient may also give a history of intermittent "coca-cola" coloured urine suggestive of this. Thrombosis tends to be in unusual sites such as the intra-abdominal and cerebral venous circulations and is often the presenting feature. The diagnosis should be considered when thrombosis occurs in these sites. Again, examination of the full blood count for the telltale cytopenia may provide an important clue. Bilirubin, lactate dehydrogenase, haptoglobin, reticulocyte count and examination of the peripheral blood film may give an indication of underlying haemolysis. Testing for urinary

Abbreviations: DVT, deep venous thrombosis; FVL, factor V Leiden; HRT, hormone replacement therapy; OCP, oral contraceptive pill; VTE, venous

thromboembolism 
Table 1 Thrombophilic conditions and associations

\begin{tabular}{ll}
\hline Primary (inherited) & Secondary (acquired) \\
\hline Antithrombin deficiency & Pregnancy \\
Protein C deficiency & Immobility \\
Protein S deficiency & Trauma \\
Factor V Leiden & Postoperative state \\
Prothrombin 20210 mutation & Oral contraceptive pill \\
Disorders of plasmin generation & Hormone replacement therapy \\
Dysfibrinogenaemia & Antiphospholipid syndrome \\
Hyperhomocysteinaemia* & Hyperhomocysteinaemia \\
& Malignancy \\
Increased plasma concentration of & Nephrotic syndrome \\
fibrinogen and coagulation factors* & Myeloproliferative disorders \\
& Heparin-induced \\
& thrombocytopenia \\
& Paroxysmal nocturnal \\
& haemoglobinuria \\
& Behçet's disease \\
& Risk of VTE increases with age \\
\hline VTE, venous thromboembolism. & \\
*Partly determined by environment. & \\
\hline
\end{tabular}

haemosiderin may identify intravascular haemolysis that is not otherwise apparent. Confirmation of paroxysmal nocturnal haemoglobinuria can be obtained by performing a Ham's test, which assesses in vitro sensitivity of red cells to complement. Flow cytometric testing for glycosylphosphatidylinositol-linked surface markers (CD55 and CD59 in the case of red cells) is a widely available confirmatory test.

\section{Antiphospholipid syndrome}

The antiphospholipid syndrome may be associated with an underlying connective tissue disorder, or may occur in isolation. Clinical clues to its presence include a history of recurrent pregnancy failure, venous, arterial or microvascular thrombosis, thrombocytopenia and livedo reticularis. Often, thrombosis is the only clinical manifestation. We recommend that testing for lupus anticoagulant and anticardiolipin antibodies/anti- $\beta 2$ glycoprotein I antibodies should be considered in cases of apparently unprovoked venous thrombosis, recurrent pregnancy failure or fetal death. This is because recurrent thrombosis is a frequent feature of the syndrome and long-term anticoagulation with warfarin is often recommended even after a single episode of VTE.

\section{INHERITED THROMBOPHILIA}

Inherited thrombophilic disorders can be identified in up to $50 \%$ of patients presenting with VTE (table 2$)^{4-19}$. The common thrombophilias occur because of highly prevalent point mutations in the genes for coagulation factor $\mathrm{V}$ (factor $\mathrm{V}$ Leiden) and prothrombin (prothrombin G20210A). Factor V Leiden results in a reduced sensitivity of activated factor $\mathrm{V}$ to its inhibitor, activated protein C. The prothrombin mutation causes increased prothrombin concentration in plasma. Both result in a hypercoagulable state and a modestly increased risk of thrombosis over background (table 2). The forms of heritable thrombophilia that are due to deficiency of one of the physiological anticoagulants (antithrombin III, protein C and protein S) are of lower prevalence. Again, heterozygotic people have an increased risk of VTE. Essentially, these genetic disorders have limited penetrance and even if manifest lead to a relatively late-onset, usually non-fatal disorder: VTE. This is an important consideration in relation to genetic counselling.

As testing for heritable thrombophilia has become widely available, it has been commonplace for patients with thrombosis (and many without) to be tested. Before the use of thrombophilia testing is discussed further, the following points should be considered:
- The currently identified inherited thrombophilic conditions are found in only about $50 \%$ of patients with VTE, the proportion varying with the cohort studied (it is lower if postoperative VTE is included) (table 2). Therefore, negative testing does not exclude heritable risk through as yet unrecognised mechanisms.

- All patients with VTE can be justifiably considered to have exhibited a prothrombotic tendency, or thrombophilia. It follows that there is no justification for treating a patient who tests negative with current tests differently from one who tests positive.

- An example of the frequent inconsistencies in testing for heritable thrombophilia stems from the observations that the $\mathrm{ABO}$ blood group is associated with venous thrombosis risk. Those with blood groups $\mathrm{A}, \mathrm{B}$ or $\mathrm{AB}$ are at higher risk than those with $\mathrm{O}^{20}$ and men have a higher risk of VTE recurrence than women. ${ }^{21}{ }^{22}$ Like factor $\mathrm{V}$ Leiden, ABO blood type and sex represent common non-modifiable risk factors, but the $\mathrm{ABO}$ group is rarely assessed in thrombophilia testing and blood group and sex do not contribute to decisions on clinical management.

- The same thrombophilic disorder can have very different clinical penetrance within families, such that test results give little guidance in determining a management plan for an individual patient (they have more relevance in determining risk on a population basis). There may be a tendency for emphasis on genetic testing to divert attention from the identification and management of modifiable risk factors in patient management.

From the above, an important consideration clearly is to what extent positive (or negative) testing justifiably alters the management of the individual patient with VTE. The next part of this review will consider the rationale for thrombophilia testing in a range of commonly encountered clinical situations, with particular emphasis on clinical decision making.

\section{Thrombophilia testing in symptomatic people (case finding)}

Patients who have had a venous thrombosis have a high prevalence of inherited thrombophilic disorders (table 2); thus thrombophilia testing can be rewarding in this group if a partial explanation is all that is desired. Before testing, however, we must give careful consideration to how the test will influence the future management of the individual.

One of the major considerations influencing management is the rate of recurrence of venous thrombosis once anticoagulation has been stopped. This is the only clinical risk assessment in symptomatic people that thrombophilia testing could have the potential to influence. If the risk of recurrence is deemed high, then consideration should be given to longterm anticoagulation, particularly if the risks associated with the recurrence of thrombosis are greater than the risks, especially of fatal or serious haemorrhage, posed by longterm anticoagulation.

In considering this issue, the thrombosis recurrence rate in patients with a first episode of VTE deserves attention. Sevenyear follow-up data from the Leiden Thrombophilia Study on 474 unselected patients with venous thrombosis have been published recently. The cumulative recurrence rate was $12.4 \%$ after 5 years, increasing to $16.5 \%$ after 7 years. ${ }^{23}$ If only patients with unprovoked thrombosis are considered, the data of Baglin et $a^{24}$ indicate a recurrence rate of almost $20 \%$ over 2 years.

Is it possible to refine the prognosis regarding risk of recurrence through testing for heritable thrombophilia? In fact, there is convincing evidence that symptomatic people with positive thrombophilia tests do not have a higher rate of 
Table 2 Common inherited thrombophilic defects, incidence and risk

\begin{tabular}{|c|c|c|c|c|c|c|}
\hline & \multirow{2}{*}{$\begin{array}{l}\text { Prevalence in } \\
\text { unselected } \\
\text { population } \\
\text { (Caucasian) }^{4}\end{array}$} & \multirow{2}{*}{$\begin{array}{l}\text { Prevalence in patients } \\
\text { presenting with first } \\
\text { episode of venous } \\
\text { thrombosis }{ }^{4} \S\end{array}$} & \multicolumn{4}{|c|}{$\begin{array}{l}\text { Annual risk of venous thrombosis in people with no history of thrombosis (people with } \\
\text { thrombophilic defects identified by family screening* or case-control studiest) } \neq\end{array}$} \\
\hline & & & Overall & Pregnancy & OCP & HRT \\
\hline $\begin{array}{l}\text { No defect } \\
\text { identified }\end{array}$ & $85 \%$ & $50 \%$ & $0.01 \% * * 5$ & $0.1 \%^{6}$ & $0.02 \% \dagger^{7}$ & $0.32 \% \dagger^{8}$ \\
\hline $\begin{array}{l}\mathrm{FVL} \\
\text { heterozygosity }\end{array}$ & $3-7 \%$ & $10-20 \%$ & $\begin{array}{l}0.05 \% \dagger \\
0.1-0.2 \%^{9-11 *}\end{array}$ & $\begin{array}{l}0.2 \%^{12} \dagger \\
2.1 \%^{13 *}\end{array}$ & $\begin{array}{l}0.1 \% \dagger^{7} \\
0.48 \%{ }^{13 *}\end{array}$ & $1.6 \% t^{8}$ \\
\hline $\begin{array}{l}\text { Prothrombin } \\
\text { gene mutation } \\
\text { (heterozygotic) }\end{array}$ & $1-3 \%$ & $5-6 \%$ & $0.13 \%^{9 *}$ & $0.5 \%^{12} \dagger$ & $0.07 \% \dagger^{7}$ & Unknown \\
\hline $\begin{array}{l}\text { Protein } C \\
\text { deficiency }\end{array}$ & $0.2-0.5 \%$ & $2-3 \%$ & $0.7 \%^{10 *}$ & $1.7 \%^{14 *}$ & Unknown & Unknown \\
\hline $\begin{array}{l}\text { Protein S } \\
\text { deficiency }\end{array}$ & $0.2-0.5 \%$ & $2-3 \%$ & $0.8 \%^{10 *}$ & $6.6 \%^{14 *}$ & Unknown & Unknown \\
\hline $\begin{array}{l}\text { Antithrombin } \\
\text { deficiency }\end{array}$ & $0.1-0.3 \%$ & $1-2 \%$ & $1.7 \%^{10 *}$ & $3 \%{ }^{14 *} 40 \% \dagger^{15}$ & Unknown & Unknown \\
\hline $\begin{array}{l}\mathrm{FVL} \\
\text { homozygosity }\end{array}$ & $0.1 \%^{7}$ & $1.5 \%^{16}$ & $0.8 \%$ & $8-16 \%^{17-19}$ & Unknown & Unknown \\
\hline $\begin{array}{l}\mathrm{FVL/PT} \\
\text { compound } \\
\text { heterozygotes }\end{array}$ & $0.1 \%$ & $2 \%^{7}$ & $0.42 \%^{9 *}$ & $4 \%^{18 *}$ & $0.17 \% \dagger^{7}$ & Unknown \\
\hline
\end{tabular}

FVL, factor V Leiden; HRT, hormone replacement therapy; OCP, oral contraceptive pill; PT, prothrombin.

*Family screening; †case-control studies.

${ }^{* *} 0.1 \%$ in those aged $>60$ years.

tFamily screening involves following up asymptomatic but thrombophilic relatives of thrombophilic probands and observing the thrombosis rate. Case-control studies compare the rate of thrombophilic defects between patients with thrombosis and healthy asymptomatic controls. An odds ratio is calculated, with the absolute risk calculated by multiplying this by the baseline risk. Case-control studies give consistently lower estimates of risk than family studies and are likely to represent the risk in thrombophilic individuals with no personal or family history of thrombosis, whereas family studies show increased risk in such an individual with a family history.

§Hyperhomocysteinaemia and increased levels of factor VIII account for 20-30\%.

Up to $50 \%$ of pregnancy-associated venous thromboembolism occurs postpartum.

recurrence than those who test negative. ${ }^{23}{ }^{24}$ Those people heterozygotic for factor V Leiden or prothrombin G20210A make up the majority of patients who have positive thrombophilia tests, and there have been several studies confirming that these thrombophilias are not associated with an increased risk of thrombosis recurrence in comparison with patients in whom none of the recognisable heritable thrombophilic conditions is found. ${ }^{25-28}$ Therefore, thrombophilia testing cannot be used to guide decisions on duration of warfarin treatment after venous thrombosis.

More doubt exists over the importance of combined genetic thrombophilic defects and deficiencies of the natural anticoagulants. Scanty data are available on the risk of thrombosis recurrence in these patients, but there is recent evidence to suggest that it is not as high as previously thought. The Procare group ${ }^{29}$ found a relative risk of thrombosis recurrence of only 1.8 (95\% confidence interval (CI) 1.0 to 6.17) in those who were homozygotic for factor $\mathrm{V}$ Leiden compared with those who were heterozygotic. Also, van den Belt ${ }^{30}$ showed a 1-year and 5-year cumulative risk of thrombosis recurrence in their cohort of patients with deficiencies of natural anticoagulants of $10 \%$ and $23 \%$, respectively. Although there was no comparison group, this compares favourably with historical controls. On the basis of this, we question the uncritical use of long-term anticoagulation after a first episode of venous thrombosis in such people, further undermining any clinical value of thrombophilia testing. By contrast, two recent papers ${ }^{23}{ }^{24}$ highlighted the relevance of clinical factors, which are easily determined at the bedside (provoked $v$ idiopathic VTE), and the risk of thrombosis recurrence.

\section{Screening}

Screening asymptomatic people for heritable thrombophilia gives us the option of taking preventive measures in those with positive tests: avoidance of the enhanced risk associated with use of the combined oral contraceptive pill (OCP) or hormone replacement therapy (HRT), or enhanced thromboprophylaxis in situations of temporary increased risk (surgery and pregnancy). The justification for this approach in a range of circumstances is discussed below.

\section{Universal population screening}

Consensus exists that screening of the general population to assess venous thrombosis risk is not cost effective. In addition, it would be likely to generate anxiety and carry a risk of the use of unnecessary and potentially harmful interventions.

\section{Selective population screening: before OCP use}

The annual risk of venous thrombosis in an otherwise healthy woman of reproductive age is around $0.01 \%$ (table 2 ). This is increased around 2-5-fold with OCP use and justifies careful assessment of thrombosis risk before prescription of this form of contraception. However, the OCP is the most acceptable and effective form of contraception for many women and a clear understanding of the absolute risk of VTE is required. The risk of OCP-related venous thrombosis in factor V Leiden (FVL) heterozygotes is multiplicative, not simply additive, when compared with the risk associated with either of these factors alone. Although case-control studies have estimated this risk at approximately $0.1-0.2 \%$ per annum ${ }^{7}$ for V Leiden heterozygotes without a personal or family history of thrombosis (up to 20 times baseline risk), the risk is substantially greater at around $0.5 \%$ per annum if FVL heterozygosity is identified through testing of an individual in whom there is a history of VTE in a first-degree relative. ${ }^{13}$ We draw three conclusions from these observations.

Firstly, most women with factor V Leiden will not have VTE even after using OCP for many years. Indeed, as 
population screening is not carried out and the family history may be negative for VTE, many factor V Leiden heterozygotes are currently using oral contraception.

Secondly, 10000 women would have to be screened and the OCP withheld in 500 otherwise healthy FVL heterozygotes to prevent one episode of VTE. A recent review concluded that this approach, when applied to all inherited thrombophilic defects, is not cost effective ( $£ 202402$ per thrombosis prevented). ${ }^{31}$ Crenin $^{32}$ also evaluated the cost of preventing death due to VTE secondary to OCP use in combination with FVL (case fatality per VTE around 1-2\%) and calculated that $>92000$ carriers would have to be identified and the pill withheld, at a cost of $>300$ million USD, to prevent one death.

Thirdly, the value of thrombophilia testing is further undermined by the current recommendation that in women with a history of VTE in a first-degree relative, use of the OCP is relatively contraindicated.

Testing for heritable thrombophilia may occasionally be of value in the above-mentioned situation-that is, before prescription of the OCP in an asymptomatic woman who has a first-degree relative with a history of VTE. The affected relative must be available and give permission for testing to be carried out. Careful counselling is required. If a heritable thrombophilia can be identified which segregates with thrombosis in the affected kindred, and the person is found to be negative for this, then it would be reasonable to prescribe the OCP on the assumption that the thrombosis risk is close to that of the general population. In fact, Lensen ${ }^{33}$ found an annual thrombosis risk of $0.56 \%$ in FVL-positive asymptomatic relatives who were identified through family screening of patients with venous thrombosis with FVL, and a rate of $0.15 \%$ in relatives who were FVL negative. The rate in FVL-negative people may be a little higher than background, possibly owing to the coinheritance of as yet unidentified thrombophilic genes in clinically affected families.

Often we are referred women who are already using the OCP who find that a relative has had VTE. In advising such women it is noteworthy that OCP-related venous thrombosis is most likely to occur in the first $6-12$ months of use. ${ }^{34}$ Thus, if a woman has been using the OCP for several years without complications, discontinuation on the basis of the family history or test results may not be justified in every case.

In conclusion, population screening before OCP use to withhold oral contraception in women who test positive is not recommended. Testing may be useful in women with a family history of thrombosis, provided a family study is possible. Pretest counselling is essential.

\section{Selective population screening: before HRT use}

Because of the greater age of women who may consider HRT use, the baseline risk for venous thrombosis is significantly higher (around $0.1 \%$ per annum). HRT is associated with an overall 2-4-fold increase in this risk, ${ }^{83}$ and around a 6-15fold increase in people heterozygotic for $\mathrm{FVL}^{8}{ }^{35}$ giving an estimated absolute risk of around $1.0 \%$ per annum. The mortality per event is likely to be $<10 \%,{ }^{36}$ indicating an estimated annual risk of death in association with HRT and FVL heterozygosity of around $0.1 \%$. This risk is likely to be replicated for the other inherited thrombophilic defects, although it may be higher in women with combinations of defects and in homozygotes.

Screening for heritable thrombophilia in unselected women before HRT use and withholding the prescription in those who test positive may be a cost-effective screening strategy ( $€ 6824$ per event prevented), ${ }^{31}$ although this approach has not been widely implemented. This is likely to be because women with severe menopausal symptoms affecting quality of life are willing to accept this risk. As with OCP use, the greatest risk is in the first 6-12 months of use. ${ }^{37}$

Evidence shows that transdermal HRT preparations are associated with a lesser thrombotic risk than oral preparations. ${ }^{38}$ Although this has not been tested in the clinical situation in women with heritable thrombophilia, if the use of HRT is unavoidable, a transdermal preparation may be preferred.

In women with a family history of venous thrombosis who require HRT, a family study to identify any heritable thrombophilia can be considered, after careful counselling. This may allow HRT prescription if the person is found to be negative for a thrombophilic defect, which segregates with thrombosis in the affected kindred.

\section{Selective population screening: pregnancy}

In addition to being associated with VTE in pregnancy, heritable thrombophilia has been linked to adverse pregnancy outcomes, including fetal loss, placental abruption, pre-eclampsia and intrauterine growth retardation. Screening in pregnancy is appealing as it gives the opportunity to provide antithrombotic treatment to reduce the risk of these events in at-risk women. However, the use of such a screening strategy is not supported on the basis of current knowledge. Wu et al, ${ }^{31}$ in a cost-benefit analysis, found that screening unselected women before pregnancy is not cost effective, at £81 436 per event prevented. This model included adverse pregnancy outcome as an event (thus the figure for DVT prevention alone is likely to be much higher) and assumed use of antepartum prophylaxis with heparin in all women who test positive.

In women who have had a previous VTE there is no clear benefit to thrombophilia testing before pregnancy. This is because the VTE recurrence rate in pregnancy is low, necessitating the exposure of a large number of women to heparin prophylaxis throughout pregnancy to prevent a single episode of VTE. In addition, the evidence does not suggest that identification of heritable thrombophilia can usefully influence management. Brill-Edwards et al ${ }^{39}$ withheld antepartum prophylaxis in 125 women with a previous single episode of DVT. All women were given postpartum VTE prophylaxis for 6 weeks. Only $3(2.4 \%)$ of these women had antepartum DVT recurrence. Of the 36 women whose prior event was considered idiopathic, $2(5.5 \%)$ had antepartum recurrence, whereas only 1 ( $1.7 \%)$ of 59 women whose prior event was associated with a temporary risk factor had antepartum recurrence. Notably, there were also three postpartum recurrences despite prophylaxis (two in the idiopathic group and one in the temporary risk group). These data indicate that the risk of VTE recurrence in pregnancy is quite low. Furthermore, Pabinger et $a l^{40}$ observed 109 women who had previous VTE through 197 pregnancies without antepartum prophylaxis. They observed 8 (4.1\%) antepartum recurrences. Of the 62 women, 4 (6.2\%) who tested positive for thrombophilia had antepartum recurrence compared with $4(10.2 \%)$ of 39 women who tested negative. Interestingly, most of the recurrences were in women whose previous VTE was provoked by the OCP (seven recurrences in the 72 women whose previous events were OCP related), whereas there was only one recurrence in the 37 women whose previous event was a non-OCP temporary risk factor and no recurrence in the 15 women whose previous event was spontaneous.

Severe thrombophilias (eg antithrombin deficiency, homozygosity for factor $\mathrm{V}$ Leiden and $\mathrm{V}$ Leiden/prothrombin mutation double heterozygotes) may have a higher absolute risk of pregnancy-associated thrombosis. Owing to their low prevalence, estimates of risk have been inconsistent. Although a VTE risk of $40 \%$ in pregnancy has been suggested 
in antithrombin-deficient women, ${ }^{15}{ }^{6}$ Friederich et al ${ }^{14}$ followed up 13 antithrombin-deficient women through a total of 33 pregnancies and observed only one thrombotic event (3\%). A recent study found that 3 of $19(15.8 \%)$ women with homozygotic factor V Leiden and 2 of 50 (4\%) women with double heterozygosity developed pregnancy-associated venous thrombosis, although all but one of these events occurred postpartum. ${ }^{18}$ These at-risk women cannot be efficiently identified without adopting a strategy of routine testing. Targeting tests to women with the strongest family histories of VTE is a possibility, but the cost effectiveness of such an approach has not been tested.

\section{Important practical pitfalls in testing}

Uncritical interpretation of laboratory results leads to misdiagnosis and thrombophilia testing exemplifies this. If erroneous and overdiagnosis are to be avoided, the following points must be recognised:

- Normal ranges for antithrombin and proteins $\mathrm{C}$ and $\mathrm{S}$ are wide and patients with deficiency may have levels that are only slightly below normal. Repeat testing is often required for diagnostic confidence. For example, laboratory quality assurance data have shown that for protein $\mathrm{S}$ in particular the rate of laboratory error in diagnosis can be as high as $20 \%{ }^{41}$

- Pregnancy induces a state of resistance to the anticoagulant effect of activated protein $\mathrm{C}$, which mimics the presence of factor V Leiden.

- Pregnancy and OCP use lead to a fall in plasma protein S concentration.

- Antithrombin concentration is reduced in acute thrombosis, by heparin treatment and in pre-eclampsia.

- Proteins $\mathrm{C}$ and S are vitamin $\mathrm{K}$ dependent and their concentrations are reduced by warfarin treatment.

Even if the above potential pitfalls are avoided, there is no indication to test for heritable thrombophilia at presentation with acute VTE, as management is not affected by the results.

\section{Genetic counselling}

Testing for thrombophilia represents genetic testing for a generally non-fatal disorder of limited penetrance. Positive results, present in a high proportion of the healthy general population, may induce undue anxiety about future health and with respect to the heritability of the abnormality. People are prone to overestimate the thrombosis risk if they test positive, and believe they have insufficient information about the abnormality. Many patients believe that their healthcare providers do not understand the condition..$^{42}$ This emphasises the importance of counselling people before embarking on thrombophilia testing. In our view, the uncritical implementation of genetic tests for thrombophilia without prior discussion is commonplace and insupportable. Good clinical practice demands that tests are carried out for carefully considered clinical reasons and that doctors must be in a position to give their patients an accurate and thorough understanding of the implications of results, be they normal or abnormal.

\section{CONCLUSIONS}

Thrombophilia has both acquired and inherited causes. The clinical history, physical examination and some directed investigations may be used to assess acquired thrombophilia. Tests for heritable thrombophilia are often used inappropriately and non-selectively. We would encourage clinicians to carefully weigh the benefits, pitfalls and unwanted consequences before committing scarce resources to the performance of tests that are rarely likely to justifiably influence clinical management, and may generate anxiety. It is our
Table 3 Our suggestions of situations where testing for heritable thrombophilia may have clinical utility

\begin{tabular}{ll}
\hline Clinical situation & Outcome \\
\hline $\begin{array}{l}\text { Patient wishing to } \\
\text { use OCP but has }\end{array}$ & $\begin{array}{l}\text { Consider OCP if patient found negative for } \\
\text { documented heritable thrombophilia within the }\end{array}$ \\
$\begin{array}{l}\text { Patient wishing to } \\
\text { use HRT but has }\end{array}$ & $\begin{array}{l}\text { Consily } \\
\text { documented heritable thrombophilia within the } \\
\text { family history of VTE }\end{array}$ \\
family
\end{tabular}

HRT, hormone replacement therapy; OCP, oral contraceptive pill;

VTE, venous thromboembolism.

\section{Further reading}

1. Baglin $T$, Luddington $R$, Brown $K$, et al. Incidence of recurrent venous thromboembolism in relation to clinical and thrombophilic risk factors: prospective cohort study. Lancet 2003;362:523-6.

2. Brill-Edwards P, Ginsberg JS, Gent M, et al. Safety of withholding heparin in pregnant women with a history of venous thromboembolism. N Engl J Med 2000;343: 1439-44.

3. Christiansen SC, Cannegieter SC, Koster T, et al. Thrombophilia, clinical factors, and recurrent venous thrombotic events. JAMA 2005;293:2352-61.

4. Vossen CY, Conard J, Fontcuberta J, et al. Risk of a first venous thrombotic event in carriers of a familial thrombophilic defect. The European Prospective Cohort on Thrombophilia (EPCOT). J Thromb Haemost 2005;3:459-64.

5. Walker ID, Greaves $M$, Preston FE, et al. Investigation and management of heritable thrombophilia. $\mathrm{Br} J$ Haematol 2001;114:512-28.

belief that concentration on the clinical history, physical examination and appropriate testing for acquired prothrombotic disorders is appropriate in most cases of VTE.

\section{SELF-ASSESSMENT QUESTIONS (TRUE (T)/FALSE (F); ANSWERS AFTER THE REFERENCES)}

1. Around $4-6 \%$ of northern Europeans are heterozygotic for factor $\mathrm{V}$ Leiden $(\mathrm{T} / \mathrm{F})$

2. The $A B O$ blood group is significantly associated with venous thrombosis (T/F)

3. It is generally accepted that exhaustive screening for occult malignancy is not justified in patients who present with unprovoked venous thrombosis (T/F)

4. A negative thrombophilia screen excludes heritable thrombophilia (T/F)

5. Heritable thrombophilia is associated with a fivefold or greater lifelong increase in risk of VTE (T/F)

6. The majority of pregnancy-related venous thrombosis occurs antepartum (T/F)

7. Oral contraceptive pill use is associated with an overall tenfold increase in VTE risk over baseline (T/F)

8. Factor $V$ Leiden has been shown to predict for recurrence of venous thrombosis (T/F)

9. Anticoagulation with warfarin lowers plasma protein $C$ concentration (T/F)

10. Results of tests for inherited thrombophilia usefully inform the management of acute VTE (T/F) 


\section{Authors' affiliations}

L Merriman, Department of Haematology, Aberdeen Royal Infirmary, Aberdeen, UK

M Greaves, Department of Medicine and Therapeutics, Aberdeen University, Aberdeen, UK

Competing interests: None declared.

\section{REFERENCES}

1 Walker ID, Greaves M, Preston FE. Investigation and management of heritable thrombophilia. Br J Haematol 2001;114:512-28.

2 Hettiarachchi RJ, Lok J, Prins $M H$, et al. Undiagnosed malignancy in patients with deep vein thrombosis: incidence, risk indicators, and diagnosis. Cancer 1998:83:180-5.

3 Piccioli A, Lensing AW, Prins MH, et al. Extensive screening for occult malignant disease in idiopathic venous thromboembolism: a prospective randomized clinical trial. J Thromb Haemost 2004:2:884-9.

4 Lensing AW, Prandoni P, Prins MH, et al. Deep-vein thrombosis. Lancet 1999;353:479-85.

5 Samuelsson E, Hagg S. Incidence of venous thromboembolism in young Swedish women and possibly preventable cases among combined oral contraceptive users. Acta Obstet Gynecol Scand 2004;83:674-81.

6 McColl MD, Ramsay JE, Tait RC, et al. Risk factors for pregnancy associated venous thromboembolism. Thromb Haemost 1997;78:1183-8.

7 Emmerich J, Rosendaal FR, Cattaneo M, et al. Combined effect of factor V Leiden and prothrombin 20210A on the risk of venous thromboembolismpooled analysis of 8 case-control studies including 2310 cases and 3204 controls. Study Group for Pooled-Analysis in Venous Thromboembolism. Thromb Haemost 2001;86:809-16.

8 Rosendaal FR, Vessey M, Rumley A, et al. Hormonal replacement therapy prothrombotic mutations and the risk of venous thrombosis. $\mathrm{Br} J$ Haematol 2002;116:851-4

9 Martinelli I, Bucciarelli P, Margaglione $M$, et al. The risk of venous thromboembolism in family members with mutations in the genes of factor $V$ or prothrombin or both. Br J Haematol 2000:111:1223-9.

10 Vossen CY, Conard J, Fontcuberta J, et al. Risk of a first venous thrombotic event in carriers of a familial thrombophilic defect. The European Prospective Cohort on Thrombophilia (EPCOT). J Thromb Haemost 2005; 3:459-64.

11 Heit JA, Sobell JL, Li H, et al. The incidence of venous thromboembolism among Factor $V$ Leiden carriers: a community-based cohort study. J Thromb Haemost 2005;3:305-11

12 Gerhardt A, Scharf RE, Beckmann MW, et al. Prothrombin and factor V mutations in women with a history of thrombosis during pregnancy and the puerperium. N Engl J Med 2000;342:374-80.

13 Middeldorp S, Henkens CM, Koopman MM, et al. The incidence of venous thromboembolism in family members of patients with factor $\mathrm{V}$ Leiden mutation and venous thrombosis. Ann Intern Med 1998;128:15-20.

14 Friederich PW, Sanson BJ, Simioni P, et al. Frequency of pregnancy-related venous thromboembolism in anticoagulant factor-deficient women: implications for prophylaxis. Ann Intern Med 1996;125:955-60.

15 Pabinger I, Schneider B. Thrombotic risk in hereditary antithrombin III, protein $\mathrm{C}$, or protein $\mathrm{S}$ deficiency. A cooperative, retrospective study. Gesellschaft fur Thrombose- und Hamostaseforschung (GTH) Study Group on Natural Inhibitors. Arterioscler Thromb Vasc Biol 1996;16:742-8.

16 Rosendaal FR, Koster T, Vandenbroucke JP, et al. High risk of thrombosis in patients homozygous for factor $\mathrm{V}$ Leiden (activated protein $\mathrm{C}$ resistance). Blood 1995;85:1504-8.

17 Pabinger I, Nemes L, Rintelen C, et al. Pregnancy-associated risk for venous thromboembolism and pregnancy outcome in women homozygous for factor V Leiden. Hematol J 2000;1:37-41

18 Martinelli I, Legnani C, Bucciarelli $\mathrm{P}$, et al. Risk of pregnancy-related venous thrombosis in carriers of severe inherited thrombophilia. Thromb Haemost 2001;86:800-3.

19 Middeldorp S, Libourel EJ, Hamulyak K, et al. The risk of pregnancy-related venous thromboembolism in women who are homozygous for factor $V$ Leiden. Br J Haematol 2001;113:553-5.

20 Tirado I, Mateo J, Soria JM, et al. The ABO blood group genotype and factor VIII levels as independent risk factors for venous thromboembolism. Thromb Haemost 2005;93:468-74.

21 Kyrle PA, Minar E, Bialonczyk C, et al. The risk of recurrent venous thromboembolism in men and women. N Engl J Med 2004;350:2558-63.

22 Baglin T, Luddington R, Brown K, et al. High risk of recurrent venous thromboembolism in men. J Thromb Haemost 2004;2:2152-5.
23 Christiansen SC, Cannegieter SC, Koster T, et al. Thrombophilia, clinical factors, and recurrent venous thrombotic events. JAMA 2005;293:2352-61.

24 Baglin $T$, Luddington R, Brown K, et al. Incidence of recurrent venous thromboembolism in relation to clinical and thrombophilic risk factors: prospective cohort study. Lancet 2003;362:523-6.

25 Eichinger S, Weltermann A, Mannhalter C, et al. The risk of recurrent venous thromboembolism in heterozygous carriers of factor $V$ Leiden and a first spontaneous venous thromboembolism. Arch Intern Med 2002; 162:2357-60.

26 Mansilha A, Araujo F, Severo M, et al. Genetic polymorphisms and risk of recurrent deep venous thrombosis in young people: prospective cohort study. Eur J Vasc Endovasc Surg 2005;30:545-9.

27 De Stefano V, Martinelli I, Mannucci PM, et al. The risk of recurrent venous thromboembolism among heterozygous carriers of the G20210A prothrombin gene mutation. Br J Haematol 2001;113:630-5.

28 Rintelen C, Pabinger I, Knobl P, et al. Probability of recurrence of thrombosis in patients with and without factor $\mathrm{V}$ Leiden. Thromb Haemost 1996;75:229-32.

29 Procare G. Is recurrent venous thromboembolism more frequent in homozygous patients for the factor $\mathrm{V}$ Leiden mutation than in heterozygous patients? Blood Coagul Fibrinolysis 2003;14:523-9.

30 van den Belt AG, Sanson BJ, Simioni $P$, et al. Recurrence of venous thromboembolism in patients with familial thrombophilia. Arch Intern Med 1997; 157:2227-32.

31 Wu O, Robertson L, Twaddle S, et al. The Thrombosis: Risk and Economic Assessment of Thrombophilia Screening (TREATS) Study. Screening for thrombophilia in high-risk situations: a meta-analysis and cost-effectiveness analysis, Br J Haematol 2005;131:80-90.

32 Creinin MD, Lisman R, Strickler RC. Screening for factor V Leiden mutation before prescribing combination oral contraceptives. Fertil Steril 1999:72:646-51.

33 Lensen RP, Bertina RM, de Ronde $\mathrm{H}$, et al. Venous thrombotic risk in family members of unselected individuals with factor $V$ Leiden. Thromb Haemost 2000;83:817-21

34 Bloemenkamp KW, Rosendaal FR, Helmerhorst FM, et al. Higher risk of venous thrombosis during early use of oral contraceptives in women with inherited clotting defects. Arch Intern Med 2000; 160:49-52.

35 Cushman M, Kuller LH, Prentice R, et al. Estrogen plus progestin and risk of venous thrombosis. JAMA 2004; 292:1573-80.

36 Cushman M, Tsai AW, White RH, et al. Deep vein thrombosis and pulmonary embolism in two cohorts: the longitudinal investigation of thromboembolism etiology. Am J Med 2004;117:19-25.

37 Hoibraaten E, Qvigstad E, Arnesen H, et al. Increased risk of recurrent venous thromboembolism during hormone replacement therapy-results of the randomized, double-blind, placebo-controlled estrogen in venous thromboembolism trial (EVTET). Thromb Haemost 2000;84:961-7.

38 Scarabin PY, Oger E, Plu-Bureau G, et al. Differential association of oral and transdermal oestrogen-replacement therapy with venous thromboembolism risk. Lancet 2003;362:428-32.

39 Brill-Edwards P, Ginsberg JS, Gent $M$, et al. Safety of withholding heparin in pregnant women with a history of venous thromboembolism. N Engl J Med 2000;343:1439-44

40 Pabinger I, Grafenhofer H, Kaider A, et al. Risk of pregnancy-associated recurrent venous thromboembolism in women with a history of venous thrombosis. J Thromb Haemost 2005;3:949-54.

41 Favaloro EJ. Learning from peer assessment: the role of the external quality assurance multilaboratory thrombophilia test process. Semin Thromb Hemost 2005;31:85-9.

42 Hellmann EA, Leslie ND, Moll S. Knowledge and educational needs of individuals with the factor V Leiden mutation. J Thromb Haemost 2003;1:2335-9.

\section{ANSWERS}

1. True, it is a common point mutation in Caucasian populations; 2 . True-subjects with non-O blood group have an approximate twofold increase in venous thrombosis risk compared with Group O; 3. True; 4. False-around 50\% of people who are clinically thrombophilic have negative thrombophilia tests; 5. True-the thrombosis risk ranges from around $0.1 \%$ per annum for factor $\mathrm{V}$ Leiden to $1 \%$ per annum for those with deficiencies in the natural anticoagulants; 6 . True; 7. False-the risk is increased by around 2-5-fold; 8. False; 9. True; 10. False 